\title{
Gastric cancer: prevention and treatment of peritoneal metastases
}

\author{
Paul H. Sugarbaker \\ Center for Gastrointestinal Malignancies, Program in Peritoneal Surface Oncology, MedStar Washington Hospital Center, \\ Washington, DC 20010, USA.
}

\author{
Correspondence to: Dr. Paul H. Sugarbaker, Center for Gastrointestinal Malignancies, Program in Peritoneal Surface Oncology, \\ MedStar Washington Hospital Center, 106 Irving St., NW, Suite 3900, Washington, DC 20010, USA. \\ E-mail: Paul.Sugarbaker@medstar.net
}

How to cite this article: Sugarbaker PH. Gastric cancer: prevention and treatment of peritoneal metastases. $J$ Cancer Metastasis Treat 2018;4:7. http://dx.doi.org/10.20517/2394-4722.2017.67

Received: 25 Nov 2017 First Decision: 3 Jan 2018 Revised: 8 Jan 2018 Accepted: 18 Jan 2018 Published: 9 Feb 2018

Science Editor: Masayuki Watanabe Copy Editor: Jun-Yao Li Production Editor: Huan-Liang Wu

\begin{abstract}
Gastric cancer is an aggressive malignancy that may metastasize through the bloodstream to the liver, through lymphatics to regional lymph nodes, or by penetration of the peritoneal lining of the stomach to result in seeding of the abdominal and pelvis surfaces. Peritoneal metastases are the most common mode of cancer dissemination. Technologies to prevent or treat peritoneal metastases from advanced gastric cancer are presented in this manuscript. The world's literature, both recent and over the past three decades, was reviewed in order to identify publications that present information regarding gastric cancer peritoneal metastases. Over one dozen randomized controlled trials to test perioperative chemotherapy for prevention of peritoneal metastases were reviewed. All of the trials performed with regional chemotherapy during or shortly after gastrectomy were positive. The clinical data regarding the treatment of peritoneal metastases diagnosed at the time of primary cancer resection or in follow-up were reviewed. Neoadjuvant intraperitoneal and systemic chemotherapy shows that some long-term survivors occur after these treatments were combined with cytoreductive surgery and gastrectomy. Similar treatments are advocated for primary gastric cancer with cytology positive for gastric cancer but no visible implants. Surgery for gastric cancer should be combined with perioperative systemic and regional chemotherapy in order to maximally benefit patients with this disease by reducing the negative impact of peritoneal metastases on survival.
\end{abstract}

Keywords: Hyperthermic intraperitoneal chemotherapy, normothermic intraoperative intraperitoneal chemotherapy, early postoperative intraperitoneal chemotherapy, intraperitoneal chemotherapy, gastric cancer, peritoneal metastases, carcinomatosis 


\section{INTRODUCTION}

Gastric cancer is the fourth most common cancer in the world with a 5 -year survival rate of $25 \%^{[1,2]}$. In follow-up, a large percentage of gastric cancer patients will develop peritoneal dissemination (up to $40 \%$ ) which results in a less than $5 \% 5$-year survival rate ${ }^{[3-5]}$. In primary gastric cancer, peritoneal metastases are a common finding present in $5 \%-20 \%$ of patients undergoing gastrectomy ${ }^{[6]}$. The peritoneum is the most common location of first recurrence in about half of patients ${ }^{[7]}$. Although the standard of care for treatment of primary gastric cancer involves surgery, intravenous chemotherapy and radiotherapy, specific treatments for peritoneal metastases are poorly defined. Possible treatments include neoadjuvant systemic chemotherapy (NAC), neoadjuvant intraperitoneal and systemic chemotherapy (NIPS), cytoreductive surgery (CRS) and perioperative chemotherapy which may include hyperthermic intraperitoneal chemotherapy (HIPEC) and/ or early postoperative intraperitoneal chemotherapy (EPIC) ${ }^{[8]}$. CRS and HIPEC/EPIC is already considered standard of care for selected patients with appendiceal peritoneal metastases, peritoneal mesothelioma, and a limited extent of peritoneal metastases from colorectal carcinomatosis ${ }^{[9-1]}$. For gastric cancer with peritoneal metastases, current treatment recommendations remain controversial. The following is an attempt to summarize the role and efficacy of NAC, NIPS, CRS and HIPEC and/or EPIC as prevention or treatment for peritoneal metastases of gastric cancer.

\section{PREVENTION OF PERITONEAL METASTASES USING PERIOPERATIVE INTRAPERITONEAL CHEMOTHERAPY}

Surgical treatment failure with resection site and intraabdominal tumors are the most common sites of first recurrence in gastric cancer after potentially curative resection ${ }^{[12-14]}$. Regardless of neoadjuvant chemotherapy or postoperative adjuvant treatment, this local-regional progression occurs ${ }^{[15]}$. The peritoneal surfaces and liver remain the major sites of recurrence with a reduced local progression when extended lymphadenectomy as compared to limited surgery is used ${ }^{[16-18]}$.

Although confined to the abdomen, peritoneal seeding has an adverse impact on survival ${ }^{[19-22]}$. Sources of recurrence after curative resection are (1) spontaneous spreading from the primary tumor; and (2) surgical trauma causing scattering of cancer cells during the surgical procedure. If serosal surface invasion has occurred within the primary tumor, then spontaneous dissemination is more common and patients are frequently found to have viable intraperitoneal cancer cells (positive cytology) ${ }^{[1,21-23]}$. Tumor cells can also seed the intraabdominal cavity during surgery according to the tumor cell entrapment hypothesis [Figure 1]. During cancer resection, there is transection of lymphatic channels, close margins of resection, and tumorcontaminated blood spillage. Marutsuka et al. ${ }^{[2]}$ identified free cancer cells in peritoneal lavage samples in patients' initial cytology negative approximately $70 \mathrm{~min}$ after dissection of lymph node metastases. Takebayashi et al. ${ }^{[25]}$ showed that gastrectomy spilled viable cancer cells into the peritoneal space in 24 of 57 patients. They concluded that surgery induces peritoneal metastases. Arita et al. ${ }^{[26]}$ determined that large amounts of intraoperative hemorrhage increased the risk of peritoneal recurrence. This may support the contention that cancer cells are present in large numbers within blood lost from the gastric cancer specimen. These iatrogenically disseminated tumor cells adhere spontaneously within minutes and vascularization is facilitated by fibrin entrapment and the wound healing process. Cytokines, such as growth factors important for wound healing, may also propel tumor progression. The tumor cell entrapment hypothesis explains part of the pathogenesis of resection site and distant peritoneal metastases. It is the theoretical basis for adjuvant perioperative intraperitoneal chemotherapy ${ }^{[27]}$.

\section{Perioperative timing of intraperitoneal chemotherapy}

The tumor cell entrapment hypothesis suggests that intraperitoneal chemotherapy must be administered perioperatively in order to access the tumor cells prior to entrapment within fibrin and conversion into cancer implants within adhesive scar tissue. If intraperitoneal chemotherapy is delayed until after the formation of adhesive scars, it will have uneven distribution and lack direct contact with viable cancer cells. 


\section{Tumor cell entrapment hypothesis \\ - resected gastric cancer -}

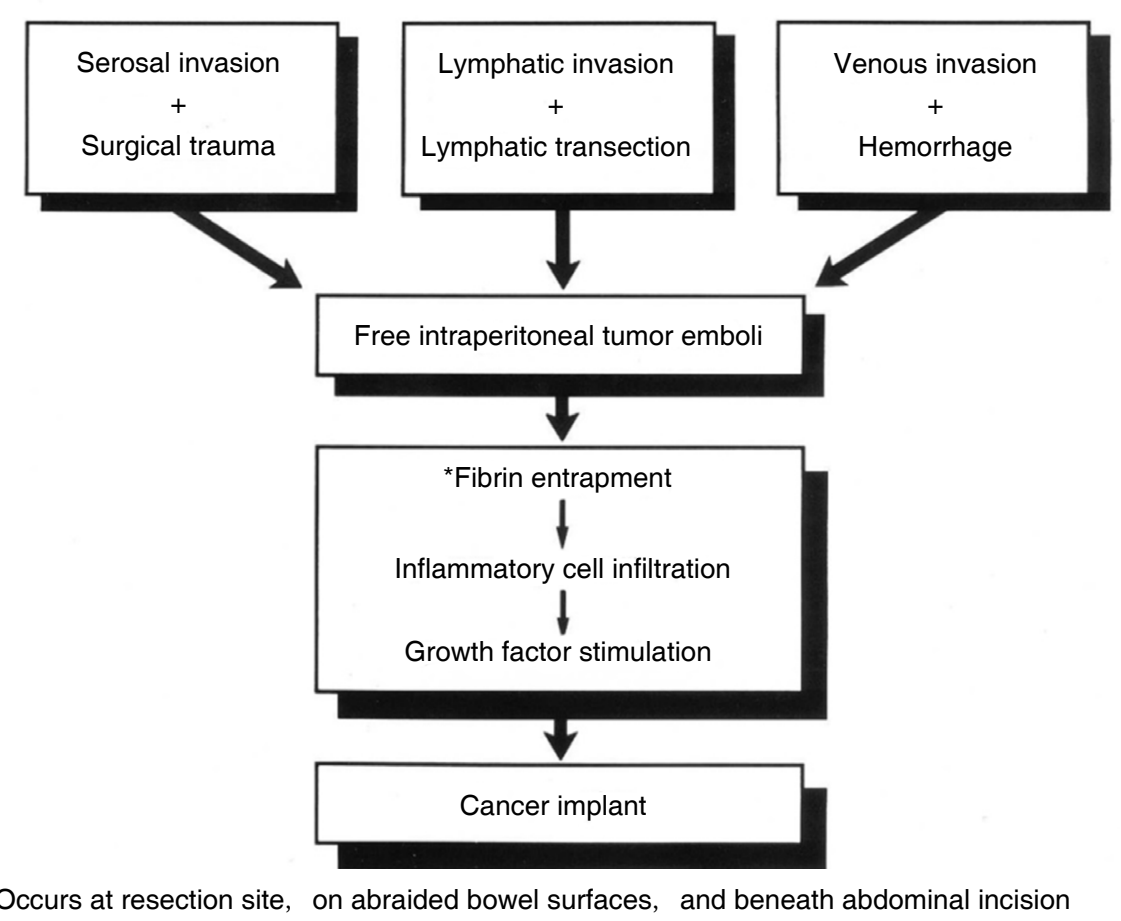

Figure 1. The tumor cell entrapment hypothesis suggests three mechanisms for microscopic residual cancer cells in patients having an R-0 gastrectomy. (From Sethna et al. ${ }^{[27]}$ with permission)

\section{PREVENTION PROTOCOLS USING PERIOPERATIVE CHEMOTHERAPY WITH GASTRECTOMY}

Perioperative intraoperative chemotherapy can eliminate progression of peritoneal implantation after curative surgery, however, it cannot treat residual disease within lymph nodes. Therefore, an adequate lymphadenectomy is essential. Intraperitoneal chemotherapy enters the peritoneal nodule by simple diffusion so it only penetrates to 1 or $2 \mathrm{~mm}^{[28]}$. It is not effective in lymph nodes. Also, peritoneal nodules larger than 1 or $2 \mathrm{~mm}$ have ineffective drug delivery and all visible nodules must be removed prior to treatment.

\section{LITERATURE REGARDING PERIOPERATIVE INTRAPERITONEAL CHEMOTHERAPY FOR} ADVANCED T-STAGE PRIMARY GASTRIC CANCER

There have been randomized and non-randomized trials about adjuvant perioperative intraperitoneal chemotherapy compared to surgery alone for resectable primary gastric cancer without peritoneal spread. Sugarbaker et al. ${ }^{[7]}$ published a meta-analysis in 2003 of articles published in English. Xu et al ${ }^{[29]}$ published a similar study in 2004. Yan et al.$^{[30]}$ published a summary of randomized control trials about adjuvant intraperitoneal chemotherapy for resectable gastric cancer in 2007. Feingold et al. ${ }^{[31]}$ published the most recent summary of non-randomized and randomized studies in English of CRS and HIPEC and/or EPIC in gastric cancer.

Yan et al. ${ }^{[30]}$ selected 10 of 13 randomized controlled trials that were judged to be of fair quality to be used in the meta-analysis. There was a survival benefit associated with HIPEC [hazard ration (HR) 0.060; 95\% CI $0.43-0.83 ; P=0.002$ ] or HIPEC with EPIC (HR 0.45; 95\% CI 0.29-0.68; $P=0.0002$ ). There was a marginal benefit with normothermic intraoperative intraperitoneal chemotherapy but no significant improvement in survival with EPIC alone or delayed postoperative intraperitoneal chemotherapy [Figure 2]. 
Table 1. Reports of patients with gastric peritoneal metastases treated by cytoreductive surgery and hyperthermic intraperitoneal chemotherapy

\begin{tabular}{|c|c|c|c|c|c|c|c|}
\hline References & Year & $\begin{array}{c}\text { No. of } \\
\text { patients }\end{array}$ & $\begin{array}{c}\text { Anticancer agent during } \\
\text { HIPEC }\end{array}$ & $\begin{array}{l}\text { Median survival } \\
\text { (months) }\end{array}$ & $\begin{array}{c}\text { 1-year } \\
\text { survival (\%) }\end{array}$ & $\begin{array}{c}\text { 3-year } \\
\text { survival (\%) }\end{array}$ & $\begin{array}{c}\text { 5-year } \\
\text { survival (\%) }\end{array}$ \\
\hline Fujimoto et $a l^{[20]}$ & $\begin{array}{l}1997 \\
\end{array}$ & 48 & $\mathrm{MMC}$ & 16 & 54 & 41 & 31 \\
\hline Hirose et $a / .{ }^{[38]}$ & 1999 & 17 & MMC-cisplatin-etoposide & 11 & 44 & -- & -- \\
\hline Rossi et al. ${ }^{[39]}$ & 2003 & 13 & MMC-cisplatin & 15 & -- & -- & -- \\
\hline $\begin{array}{l}\text { Glehen et } a I^{[40]} \\
\text { CC- } 0 \text { or } C C-1\end{array}$ & 2004 & $\begin{array}{l}49 \\
25\end{array}$ & MMC & $\begin{array}{l}10.3 \\
21.3\end{array}$ & $\begin{array}{l}48 \\
74.8\end{array}$ & $\begin{array}{l}-- \\
--\end{array}$ & $\begin{array}{l}16 \\
29.4\end{array}$ \\
\hline Hall et al. ${ }^{[34]} \mathrm{CC}-0$ & 2004 & 34 & MMC & $\begin{array}{l}-- \\
11.2\end{array}$ & $\begin{array}{l}- \\
45\end{array}$ & -- & -- \\
\hline Yonemura et al. ${ }^{[32]} \mathrm{CC}-0$ & 2005 & $\begin{array}{l}107 \\
47\end{array}$ & MMC-cisplatin-etoposide & $\begin{array}{l}11.5 \\
15.5\end{array}$ & $\begin{array}{l}-- \\
--\end{array}$ & $\begin{array}{l}-- \\
--\end{array}$ & $\begin{array}{l}6.5 \\
27\end{array}$ \\
\hline Scaringi et al ${ }^{[41]} \mathrm{CC}-0$ & 2008 & $\begin{array}{l}32 \\
8\end{array}$ & MMC-cisplatin & $\begin{array}{l}6.6 \\
15\end{array}$ & -- & -- & -- \\
\hline Glehen et al. ${ }^{[33]} \mathrm{CC}-0^{*}$ & 2010 & $\begin{array}{l}159 \\
85\end{array}$ & Various & $\begin{array}{l}9.2 \\
15\end{array}$ & $\begin{array}{l}43 \\
61\end{array}$ & $\begin{array}{l}18 \\
30\end{array}$ & $\begin{array}{l}13 \\
23\end{array}$ \\
\hline
\end{tabular}

From Sugarbaker et al ${ }^{[43]}$ with permission. CC-0: complete macroscopic cytoreduction; CC-1: residual tumor nodules < 5 mm; MMC: mitomycin C; HIPEC: hyperthermic intraperitoneal chemotherapy

Although there may be a survival benefit, perioperative intraperitoneal chemotherapy can increase morbidities. Even the most experienced peritonectomy centers that remove all macroscopic disease and then administer intraperitoneal chemotherapy have a higher morbidity and $\operatorname{cost}^{[32-34]}$. Yan et al.$^{[30]}$ discussed an association of improved overall survival with HIPEC with or without EPIC after resection of advanced gastric primary cancer, however, with EPIC there was an associated greater risk for intrabdominal abscess $(P$ $=0.003)$ and neutropenia $(P=0.007)$. Yu et al.${ }^{[35]}$ also saw an increased risk of intra-abdominal abscess with the use of EPIC compared to the control arm. Intraperitoneal chemotherapy does have less systemic toxicity as compared to systemic chemotherapy. Although individual studies did not show a significant difference in neutropenia between treatment arms, the meta-analysis demonstrated a significantly higher risk of neutropenia in the intraperitoneal chemotherapy $\operatorname{arm}^{[30]}$.

Most of the randomized studies were completed in Asia and it is unknown if they can be compared with disease in Western areas. Perioperative chemotherapy may be of greater benefit in Western patients with more advanced disease and less lymph nodes dissected. Data does suggest a role of HIPEC with or without EPIC to improve overall survival for advanced primary gastric cancer with advanced T-stage and no peritoneal metastases. A prospective multi-institutional randomized controlled trial with well-defined eligibility criteria, interventions and end-points is currently in progress in France (D2 resection \pm HIPEC) in locally advanced gastric carcinoma, GASTRICHIP, ClinicalTrials.gov Identifier: NCT01882933.

\section{TREATMENT PROTOCOLS FOR GASTRIC CANCER WITH PERITONEAL METASTASES}

Gastric cancer with peritoneal metastases has been considered a terminal condition. Prospective studies had a median survival of less than 6 months ${ }^{[36]}$. Although response rates to systemic chemotherapy regimens have improved, there has not been a similar reflection in survival rates ${ }^{[37]}$. There may be some effective palliation of gastric cancer resections in patients with peritoneal metastases, however there is no long-term improvement in survival.

\section{CYTOREDUCTIVE SURGERY AND HIPEC AS AN EFFECTIVE STRATEGY}

There is potential for long-term survival for patients with gastric cancer and peritoneal metastases with the combined use of CRS and HIPEC. There are single institutional data and phase II studies that support use of this strategy [Table 1] ${ }^{[31-34,38-41]}$. Glehen et al. ${ }^{[33]}$ studied 159 patients with a median follow-up of 20.4 months. There was a median overall survival of 9.2 months but the 5 -year survival rate was $13 \%$. Although CRS and HIPEC in gastric cancer with peritoneal metastases is less effective than with other 


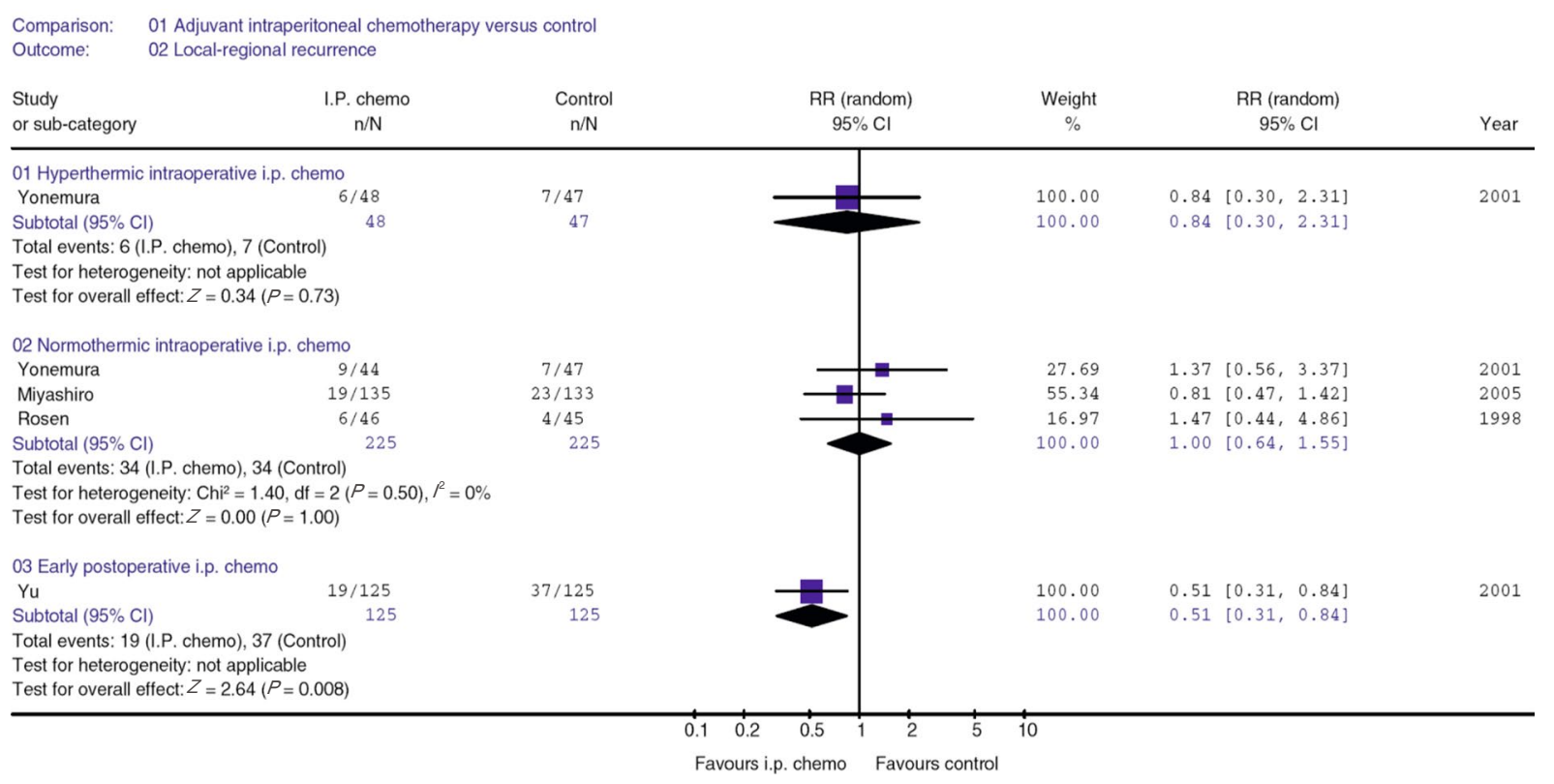

Figure 2. Forest plot of the relative risk (RR) of the local-regional recurrence with adjuvant intraperitoneal (IP) chemotherapy versus controls for advanced gastric cancer. The studies were analyzed according to the regimens of intraperitoneal chemotherapy used. The estimate of the RR of each individual trial corresponds to the middle of the squares and horizontal line gives the $95 \%$ confidence interval $(\mathrm{Cl})$. On each line, the numbers of events, expressed as a fraction of the total number randomized, are shown for both treatment groups. For each subgroup the sum of the statistics, along with the summary RR, is represented by the middle of the solid diamonds. A test of heterogeneity between the trials within a subgroup is given below the summary statistics. (From Yan et al. ${ }^{[30]}$ with permission)

gastrointestinal malignancies, there were a few long-term survivors. Gastric cancer is a more aggressive disease. Gastric cancer patients with peritoneal metastases treated with CRS and HIPEC were the only patients that reported a 5-year survival ${ }^{[39-43]}$.

These studies have shown that strict patient selection criteria are necessary. The extent of peritoneal metastases as measured by Sugarbaker's peritoneal cancer index (PCI) significantly influences survival and is correlated with the completeness of cytoreduction ${ }^{[4]}$. Cytoreductive surgery must reduce the residual disease to a minimum for intraperitoneal chemotherapy to be effective (due to minimal chemotherapy penetration). Glehen $e$ al $^{[33]}$ demonstrated a 5-year survival of $23 \%$ with median survival of 15 months in patients after a complete macroscopic resection [Figure 3]. Yonemura et al. ${ }^{[45]}$ demonstrated a similar $27 \%$-year survival rate and 15.5-month median survival. Hall et al. ${ }^{[34]}$ reported a 11.2-month overall survival after CRS and HIPEC with mitomycin C, however there was no patient alive after 2 years who had residual disease at CRS. CRS with no residual disease burden is essential for effective HIPEC. HIPEC with macroscopic disease burden does not improve survival more than 6 to 8 months. HIPEC can have morbidity and therefore should not be used for patients with bulky residual disease ${ }^{[46]}$. Palliative use for ascites may always be considered ${ }^{[45,47]}$.

Even if cytoreduction is incomplete, HIPEC is less useful for patients with high burden of peritoneal metastatic disease as measured by PCI. Glehen et al. ${ }^{[33]}$ showed that one of the strongest prognostic factors was extent of carcinomatosis. When the PCI was greater than 12, despite a complete cytoreduction there were no survivors greater than 3 years [Figure 4]. Fujimoto et al ${ }^{[20]}$ reported 40\%-50\% 5-year survival for limited peritoneal metastases but only an 18\% 1-year survival for patients with extensive peritoneal metastases. Cytoreduction with HIPEC in gastric cancer patients with a greater than 12 PCI score may be contraindicated.

Yang et al. ${ }^{[46]}$ has provided the first and only phase III study regarding CRS and HIPEC in gastric cancer presenting with peritoneal metastases. They used cisplatin $(120 \mathrm{mg})$ and mitomycin C (30 mg) in $6000 \mathrm{~mL}$ of normal saline at $43^{\circ} \mathrm{C}$ for $60-90 \mathrm{~min}$. Median follow-up was 32 months and $97.1 \%$ (33 of 34) of patients 


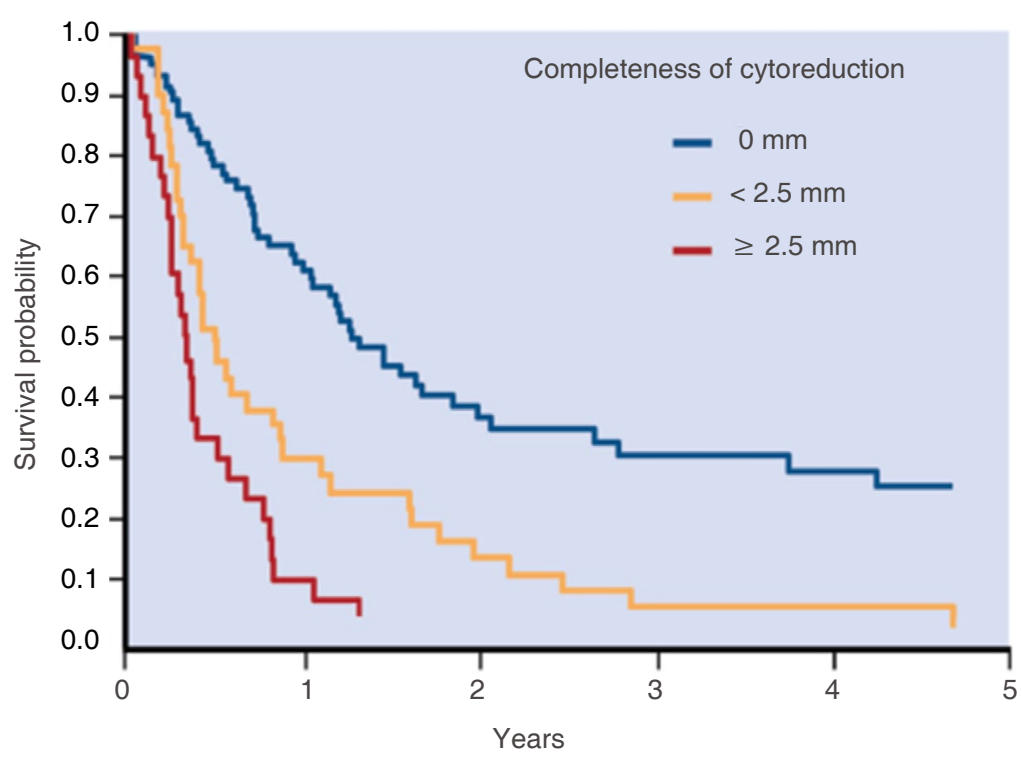

Figure 3. Overall survival of 159 patients treated by cytoreductive surgery and hyperthermic intraperitoneal chemotherapy according to completeness of cytoreductive surgery. (From Glehen et al. ${ }^{[33]}$ with permission)

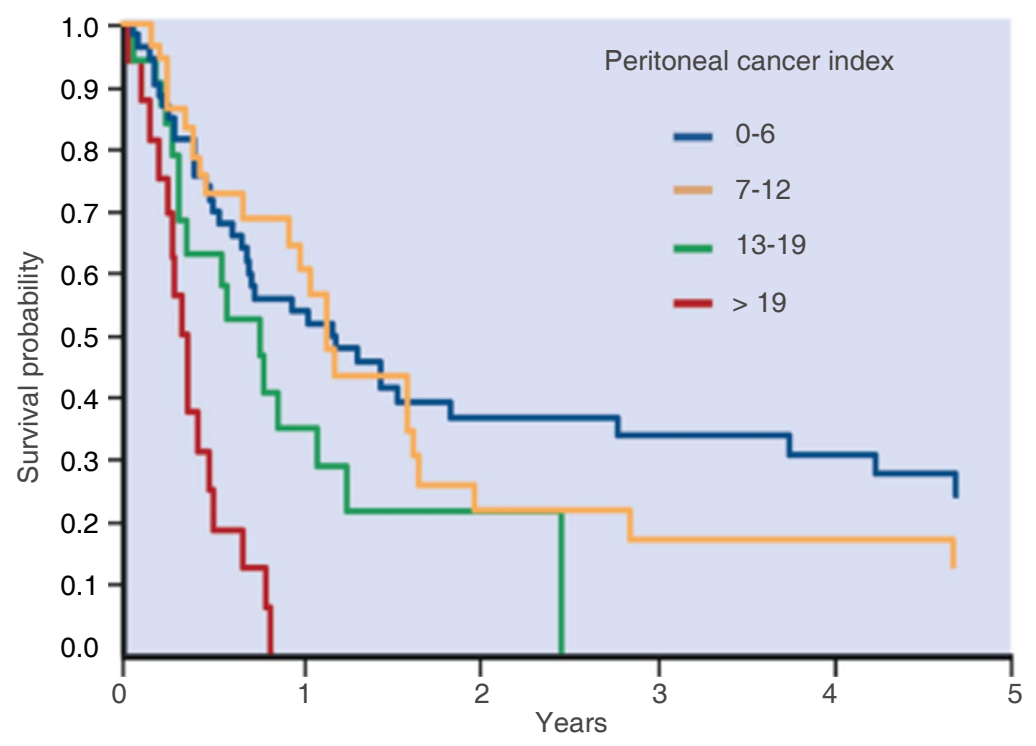

Figure 4. Overall survival of 159 patients treated by complete cytoreductive surgery according to extent of peritoneal metastases assessed by the peritoneal cancer index. (From Glehen et al. ${ }^{[33]}$ with permission)

after CRS died as compared to $85.3 \%$ (29 of 34) of CRS with HIPEC patients who died. Median survival was 6.5 months (95\% CI 4.8-8.2 months) after CRS as compared to 11 months (95\% CI 10.0-11.9 months) in CRS with HIPEC group $(P=0.046)$. There was similar morbidity between the groups. The independent predictors in a multivariate analysis for improved survival were synchronous peritoneal metastases, CC 0-1 cytoreduction, more than 6 cycles of systemic chemotherapy, and no adverse events. Glehen et al. ${ }^{[48]}$ suggested that HIPEC should be reserved for patients with limited peritoneal carcinomatosis. Also, the prognostic factors analyzed by Yang et al. ${ }^{[46]}$ suggests that it should be restricted to a limited patient population.

\section{Role of laparoscopy in patient selection for CRS and HIPEC}

Laparoscopy has been suggested as an important modality for selecting patients for aggressive treatments with CRS and HIPEC. Even today with high technology radiology studies, diagnostic laparoscopy remains 
as an important tool to detect disease below a size threshold of approximately $1 \mathrm{~cm}^{[49]}$. If a gastric cancer patient is found to have macronodular small bowel disease or would otherwise not be able to be completely cytoreduced, HIPEC would not be warranted, and the morbidity of exploratory laparotomy could be avoided. Laparoscopy may establish that patients have very limited peritoneal metastases $(\mathrm{PCI} \leq 6)$ and should be considered for CRS and HIPEC ${ }^{[50,51]}$. Recent randomized trials suggest that neoadjuvant chemotherapy should be used for gastric cancer patients free of peritoneal disease ${ }^{[52]}$. Laparoscopy may exclude patients with peritoneal metastases who would not benefit from aggressive neoadjuvant chemotherapy that is unlikely to improve their survival.

\section{NEOADJUVANT INTRAPERITONEAL AND SYSTEMIC CHEMOTHERAPY}

In medically fit patients with gastric cancer with peritoneal metastases systemic chemotherapy may be recommended. Chemotherapy can provide palliation, improve survival, and improve quality of life compared to best supportive care in patients with metastatic disease. However, the benefits of systemic chemotherapy in gastric cancer patients with peritoneal metastases may be reduced when compared to metastatic disease at other sites. Preusser et al. ${ }^{[53]}$ demonstrated that an aggressive systemic chemotherapy regimen can have a 50\% response rate in advanced gastric cancer, however this less effective in patients with peritoneal metastases. Ajani et al. ${ }^{[54]}$ used neoadjuvant chemotherapy and reported the failure of the regimen was most common in patients with peritoneal metastases. Systemic chemotherapy alone for primary gastric cancer with peritoneal metastases is a disappointing plan of management.

Neoadjuvant chemotherapy for gastric cancer can be modified for patients with peritoneal seeding by combining systemic and intraperitoneal chemotherapy. Chemotherapy may gain access to small peritoneal cancer nodules via the systemic circulation and by diffusion from a chemotherapy solution within the peritoneal cavity. Yonemura et al. ${ }^{[55]}$ proposed a prospective phase II study to establish the efficacy and assess toxicities of NIPS chemotherapy in patients with gastric cancer with peritoneal metastases. They identified patients with peritoneal metastases by laparoscopy, laparotomy with biopsy or cytology from ascites. To qualify for NIPS, patients must have: (1) proven peritoneal seeding by histology or cytology; (2) no hematogenous or remote lymph node metastases; (3) be less than or equal to 65 years; (4) have an Eastern Clinical Oncology Group score of 2 or less; (5) adequate bone marrow, liver, cardiac, and renal function; and (6) no other severe medical comorbidities or synchronous malignancies.

Qualifying patients had a peritoneal port system (Bard Port, C.R. Bard Inc., USA) inserted into the abdominal cavity under local anesthesia with the tip placed within the cul-de-sac of Douglas.

\section{Chemotherapy regimen}

Prior to administration of chemotherapy, $500 \mathrm{~mL}$ of saline was instilled into the peritoneal cavity and fluid was removed for cytology. Taxotere $40 \mathrm{mg}$ and carboplatin $150 \mathrm{mg}$ were used for intraperitoneal chemotherapy in addition to $1000 \mathrm{~mL}$ of saline over $30 \mathrm{~min}$. Methotrexate $100 \mathrm{mg} / \mathrm{m}^{2}$ and 5 -fluorouracil $600 \mathrm{mg} / \mathrm{m}^{2}$ in $100 \mathrm{~mL}$ of saline over $15 \mathrm{~min}$ were administered intravenously the same day. This regimen was administered weekly for two cycles. After the second cycle, peritoneal wash cytology was again performed. If cytology was positive, neoadjuvant chemotherapy was continued for 2 more cycles. Peritoneal cytology testing is repeating after the fourth cycle and the process is continued as long as cytology is positive.

If cytology became negative, upper endoscopy, laparoscopy and computed tomography scan was performed. If tumors showed no demonstrable change, then 2 more cycles were administered. The number of NIPS chemotherapy cycles was controlled by the effect on the primary cancer and peritoneal cytology. Complete cytoreduction was required for prolonged survival in prior studies that examined peritoneal metastases. Therefore, the goal of the NIPS regimen was complete or near complete response of metastases on small bowel surfaces [Figure 5]. 


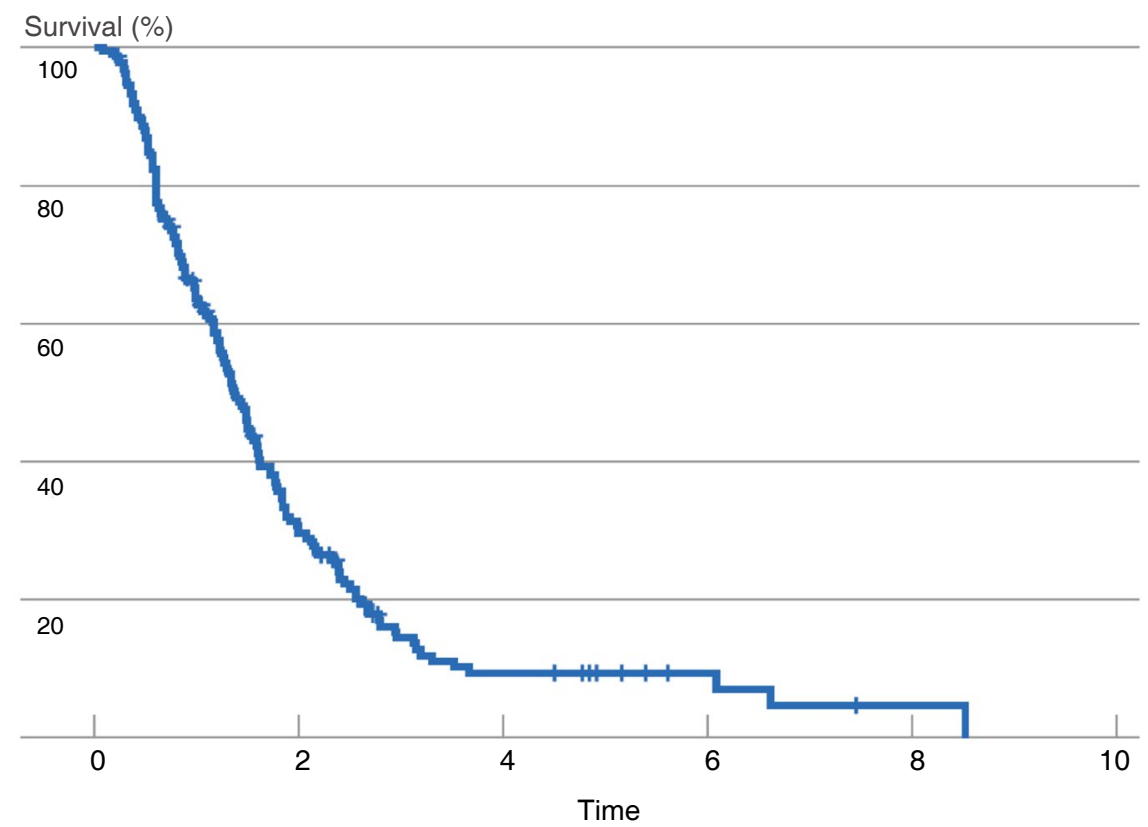

Figure 5. Overall survival in gastric cancer patients with peritoneal carcinomatosis. (From Canbay et al. ${ }^{[58]}$ with permission)

\section{SURGERY FOR GASTRIC CANCER WITH PERITONEAL METASTASES AFTER NIPS}

Gastrectomy and peritonectomy were performed if peritoneal wash cytology became negative or there was a partial response to neoadjuvant chemotherapy. If peritoneal metastases on small bowel surfaces were eliminated by NIPS, there was a possibility that gastrectomy and parietal peritonectomy could achieve a complete cytoreduction. Patients with progressive disease or who continue to have positive cytology despite 4 to 6 cycles of NIPS were not candidates for surgery.

Sugarbaker ${ }^{[56]}$ and Yonemura et al. ${ }^{[57]}$ reported the use of peritonectomy for peritoneal metastases to cytoreduce the peritoneal surface and facilitate total resection of all disease associated with the primary gastric cancer. Peritonectomies required for gastric cancer have been described ${ }^{[7]}$. The epigastric peritonectomy includes any prior midline abdominal scar with the preperitoneal epigastric fat pad, xiphoid process, round and falciform ligaments. The anterolateral peritonectomy removes the greater omentum with the anterior layer of peritoneum from the transverse mesocolon, peritoneum of the right paracolic gutter along the appendix, and the peritoneum in the right subhepatic space. Sometimes the peritoneum of the right and left paracolic gutter must also be removed [Figure 6]. The subphrenic peritonectomy takes the peritoneal surfaces from the medial half of the right and left hemidiaphragm as well as the left triangular ligament [Figure 7]. The omental bursa peritonectomy starts with cholecystectomy and then removes the peritoneal covering of the porta hepatis, hepatoduodenal ligament, and floor of the omental bursa including the peritoneum overlying the pancreas [Figure 8]. If tumor was within the cul-de-sac, a pelvic peritonectomy was also performed and electroevaporative surgery strips the peritoneum from the pouch of Douglas. Sometimes, the pelvic peritonectomy will necessitate removal of the rectosigmoid colon [Figure 9]. Some or all of these visceral resections and parietal peritonectomies were performed to completely remove visible disease.

\section{RESULTS AFTER NIPS}

Canbay et al. ${ }^{[58]}$ analyzed 194 patients treated by NIPS. Average age was $51.5 \pm 12.6$ years. One hundred and four patients had primary gastric cancer and 90 patients had recurrent PM. Peritoneal fluid cytology was 


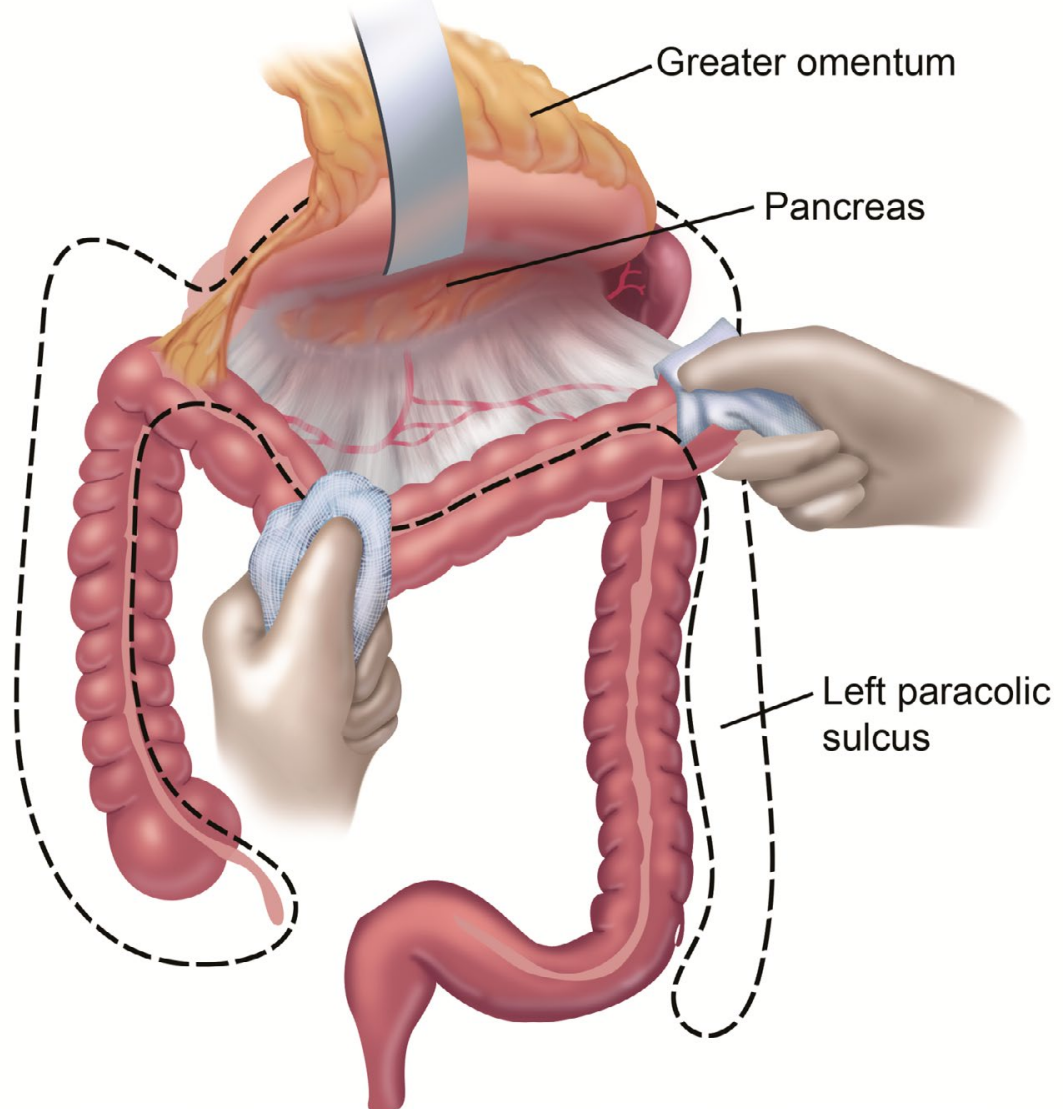

Figure 6. Anterolateral peritonectomy (From Sugarbaker et al. ${ }^{[7]}$ with permission)

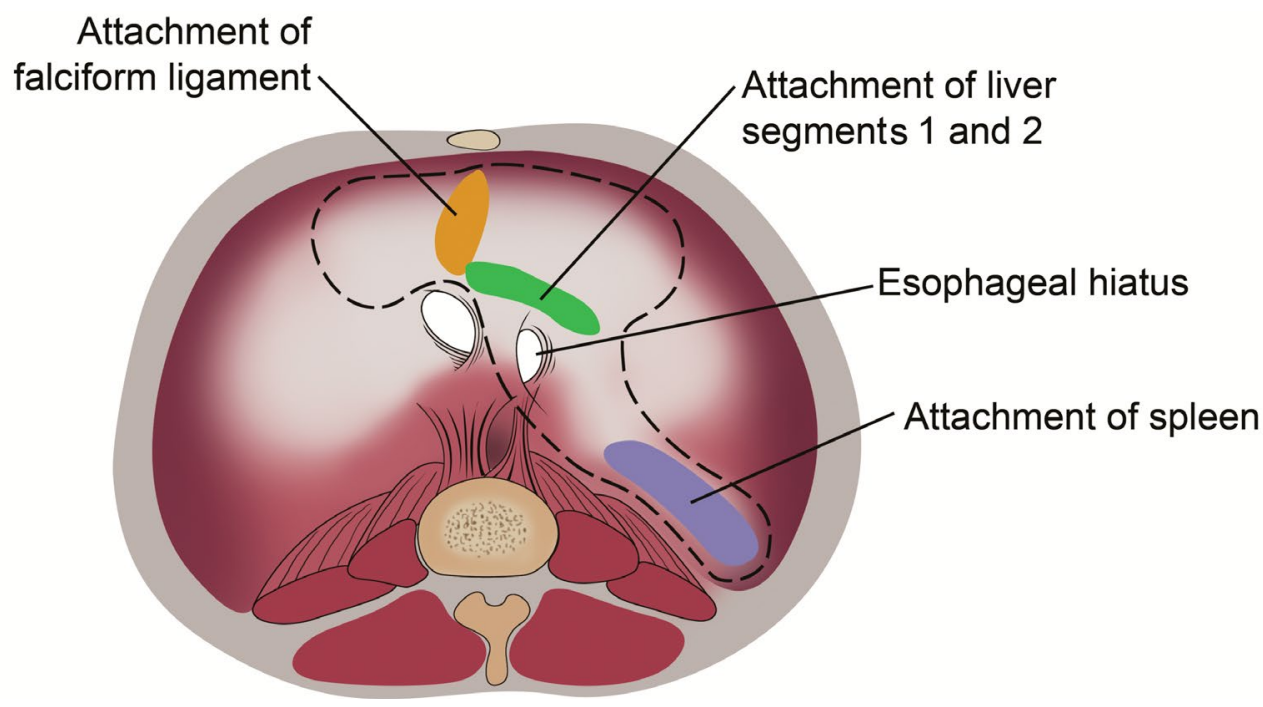

Figure 7. Subphrenic peritonectomy (From Sugarbaker et $a l .{ }^{[7]}$ with permission)

positive in 137 patients prior to NIPS chemotherapy and 152 patients were negative cytology after treatment. Complete or near-complete response was seen in 51 patients (26\%). After induction treatment, 152 (78.3\%) patients who showed negative cytology underwent CRS and HIPEC. 


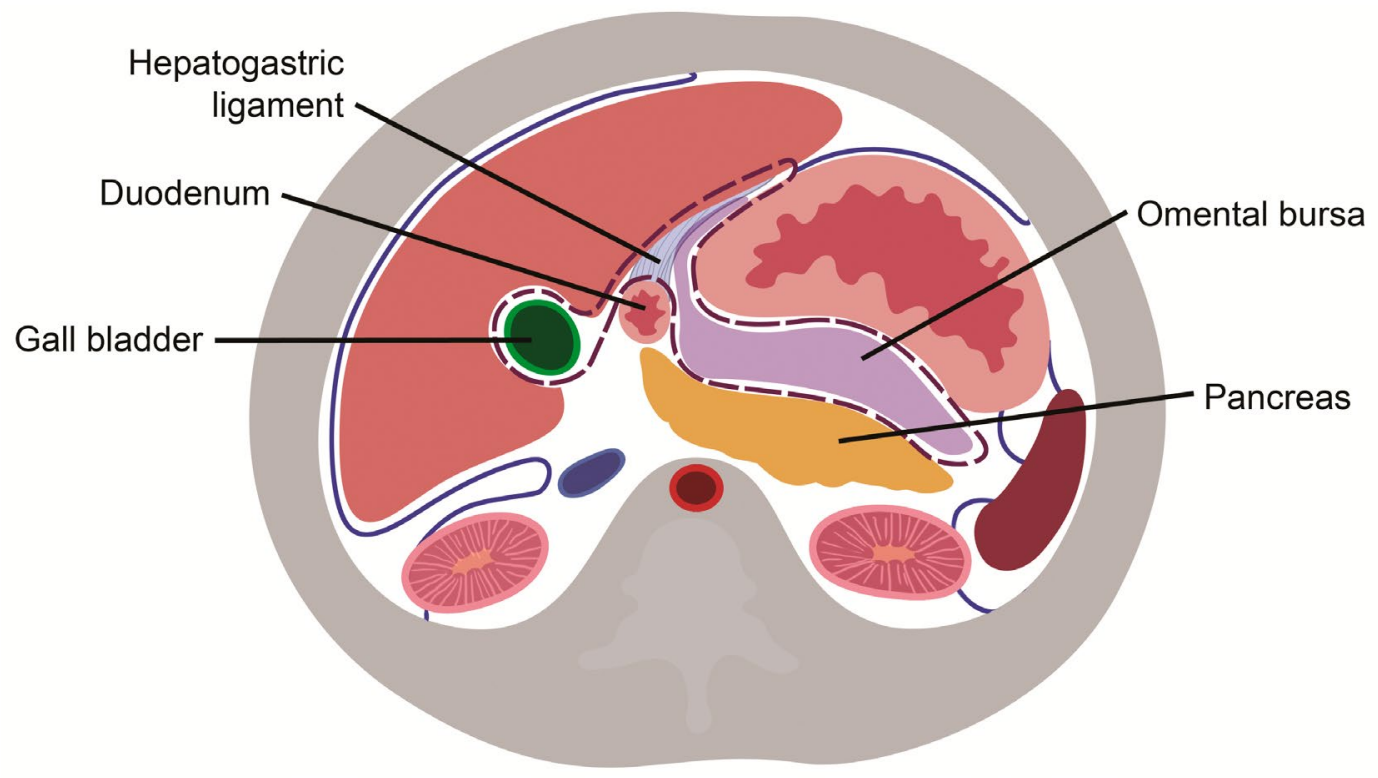

Figure 8. Omental bursa peritonectomy (From Sugarbaker et al. ${ }^{[7]}$ with permission)

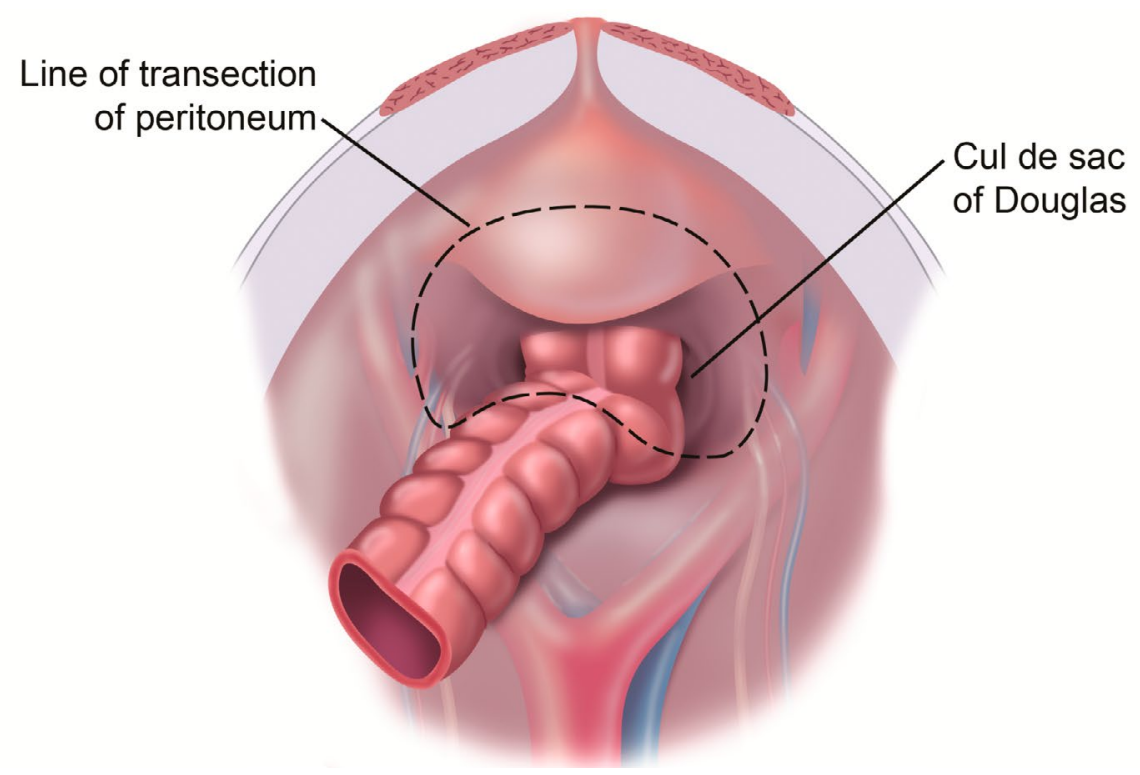

Figure 9. Pelvic peritonectomy (From Sugarbaker et al. ${ }^{[7]}$ with permission)

Operative interventions were total gastrectomy $(n=94)$, subtotal colectomy $(n=68)$, small bowel resection $(n=44)$. Left and right subdiaphragmatic peritonectomy and pelvic peritonectomy was complete in 44,31 , and 61 patients, respectively. In 102 (67.7\%) patients, of the 152 cytoreductions a complete cytoreduction was recorded.

Figure 5 demonstrates survival of the 194 patients. Median survival was 18 months for all 194 patients. For those who had received surgical intervention, median survival was 15.8 months vs. 9.7 months for patients who did not have an operation. There was a significant survival difference $(P<0.001, Z=20.98)$ between patients who underwent operative intervention $v$ s. those who did not. There was a higher median survival of 20.5 months for patients who received a complete cytoreduction $v s .10 .9$ months for those who did not have a complete cytoreduction. There was no difference between primary and recurrent disease after cytoreduction 
with a median survival of $18.0 v s .17 .4$ months, respectively. If patients did not receive an operation, median survival was similar for primary and recurrent disease as well, 9.6 vs. 8.2 months, respectively.

Another effort to use neoadjuvant intraperitoneal chemotherapy to control peritoneal metastases prior to gastrectomy was presented by Kitayama et al. ${ }^{[59]}$. They used a combination of intraperitoneal and intravenous paclitaxel along with S-1. Repeated laparoscopy was performed to assess response and gastrectomy was used selectively on patients who showed shrinkage of their peritoneal nodules as well as negative peritoneal cytology at a repeat laparoscopy. After a median number of chemotherapy cycles of 5 , gastrectomy was performed in 34 of the 64 patients. Sixty-five percent of these patients had an Ro resection. Median survival time and 1-year overall survival of the gastrectomized patients was 26.4 months and $82 \%$, respectively. Those 30 patients who did not receive gastrectomy had a median survival of 12.1 months and a $26 \% 1$-year survival. Kitayama et al. ${ }^{[59]}$ concluded that salvage gastrectomy after intravenous and intraperitoneal paclitaxel was promising even for patients with gastric cancer and peritoneal metastases with ascites.

Fujiwara et al. ${ }^{[60]}$ reported on 18 patients with primary gastric cancer and peritoneal metastases treated with NIPS. After combined intraperitoneal and systemic chemotherapy, 14 patients showed negative peritoneal cytology and no macroscopic peritoneal metastases. The median survival time of his entire group was 24.6 months and there was no treatment-related mortality.

\section{Neoadjuvant systemic chemotherapy vs. NIPS to date}

Clinical trials comparing the beneficial effects of systemic chemotherapy using modern regimens versus NIPS chemotherapy have not occurred. No doubt, in both treatments, those patients who have a resolution of their peritoneal metastases and then go on to have a successful Ro gastrectomy have a superior outcome. Al-Batran et al. ${ }^{\left[{ }_{11}\right]}$ used neoadjuvant systemic chemotherapy followed by surgical resection in patients with limited metastatic gastric or gastroesophageal junction cancer. A small number (4 of 60, 6.7\%) had peritoneal metastases as an isolated site of metastatic disease. Nevertheless, the strategy of neoadjuvant systemic chemotherapy prior to resection of all clinical evidence of disease was similar to the NIPS strategy. In their arm B, 36 of $60(60 \%)$ of patients proceeded to surgery. Overall survival of the patients who proceeded to surgery was 31.3 months and 15.9 months for the other patients. These results are similar to the benefits of NIPS followed by cytoreductive surgery. Comparative studies at some time in the future are indicated.

\section{Adverse events from NIPS and cytoreductive surgery}

The adverse events related to combined therapies NIPS, cytoreductive surgery and then HIPEC may be less than that anticipated for a complex treatment that requires up to 6 months for completion. Problems with the intraperitoneal port are much less than in prior reports of long-term intraperitoneal chemotherapy for ovarian cancer ${ }^{[62]}$. In this report there were many catheter-related complications, most of which were caused by the extensive peritoneal adhesions. The intraperitoneal ports were placed after a major surgical intervention and only $42 \%$ of patients completed all 6 cycles of intraperitoneal chemotherapy. In contrast, catheter-related complications were rare in patients having NIPES because the ports were placed prior to any surgical intervention. Adverse effects grade 3 and 4 were reported in $9 \%$ of patients in the multi-institutional study reported by Yonemura et al. ${ }^{[63]}$ in 2012. All of these side effects were from chemotherapy and not catheter-related.

In the 194 patients reported by Canbay et al ${ }^{[58]}$ in 2014, the most common chemotherapy-related grade 3 or 4 adverse events were bone marrow suppression and diarrhea. Bone marrow suppression occurred after 3 courses in 3 patients, after 5 courses in 3 patients, and after 6 courses in 4 patients. Less common adverse events were port site infection $(n=2)$ and renal failure $(n=1)$.

Prior reports of extensive cytoreductive surgery plus HIPEC following multiple cycles of intraoperative chemotherapy showed an increased morbidity primarily a result of fistula ${ }^{[64]}$. In the multi-institution report 
of NIPS, cytoreductive surgery plus HIPEC, the grade 3 and 4 complications were $21 \%$ and mortality was $3.7 \%$. These morbidity and mortality statistics are approximately the same as reported for cytoreductive surgery plus HIPEC in the absence of NIPS ${ }^{[65,66]}$.

\section{Palliative benefits to all patients with cancerous ascites}

In the publication by Canbay et al. ${ }^{[58]}$, there was improvement in symptoms for the 78 patients who had ascites. These benefits occurred in patients with primary gastric cancer and also in patients with recurrent disease. Cunliffe ${ }^{[67]}$ hypothesized that peritoneal metastases are nourished via ascites as well as blood supply. Therefore, peritoneal implants should be treated via a combined intraperitoneal and intravenous approach. Intravenous chemotherapy has minimal effects on peritoneal metastases and intraperitoneal chemotherapy alone has a less than $30 \%$ effect on ascites ${ }^{[34-36,53,54]}$. The bidirectional chemotherapy (intraperitoneal and intravenous) have a response rate of $57 \%$ with $100 \%$ resolution of ascites.

\section{Chemotherapy agents selected for NIPS}

According to the study by Morgan et al.$^{[68]}$, the maximum tolerated dose (MTD) of intraperitoneal taxotere is $125 \mathrm{mg} / \mathrm{m}^{2}$ with no grade 3 or 4 toxicities at doses below $80 \mathrm{mg} / \mathrm{m}^{2}$. Fushida et al ${ }^{[69]}$ showed an absence of hematological toxicities after intraperitoneal taxotere at $45 \mathrm{mg} / \mathrm{m}^{2}$ given once per week. The MTD of intraperitoneal carboplatin is $500 \mathrm{mg} / \mathrm{m}^{2}$ and $300 \mathrm{mg} / \mathrm{m}^{2}$ dose was reported as safe in Japanese ovarian cancer patients ${ }^{[70,71]}$. This study safely used taxotere $40 \mathrm{mg} / \mathrm{m}^{2}$ and carboplatin $150 \mathrm{mg} / \mathrm{m}^{2}$ combined. The combined use of systemic and intraperitoneal chemotherapy had no deaths and reasonable morbidity and was effective for ascites.

In summary, NIPS should be considered in gastric cancer patients with peritoneal metastases. It has maximal benefits for small volumes of peritoneal surface metastases and is reliable treatment for symptomatic ascites. Bidirectional chemotherapy may be the preferred strategy for preoperative chemotherapy of gastric carcinomatosis.

\section{Management of primary gastric cancer with positive peritoneal cytology}

The survival of primary gastric cancer patients with positive peritoneal cytology in the absence of macroscopic peritoneal dissemination is very nearly the same ${ }^{[72]}$. The 5 -year survival rate of cytology-positive but peritoneal metastases negative patients is $2 \%$. Coccolini et al. ${ }^{[73]}$ performed a systematic review and meta-analysis concerning the effects of intraperitoneal chemotherapy and peritoneal lavage on this group of patients. Coccolini et al ${ }^{[73]}$ concluded that 2- and 5-year overall survival in patients with free cancer cells without carcinosis is increased by intraperitoneal chemotherapy. Peritoneal lavage further increases these survival rates and also it further decreases the peritoneal recurrence rate.

Shimada et al. ${ }^{[74]}$ in 2001 reported in a comparative non-randomized trial about the effects of intraoperative peritoneal lavage either associated or not with intraperitoneal chemotherapy for gastric cancer with free peritoneal cancer cells. Patients treated by intraoperative peritoneal lavage followed by intraperitoneal chemotherapy showed improved survival compared to patients treated by surgery alone or by surgery plus intraperitoneal lavage.

Kuramoto et al. ${ }^{[75]}$ reported the results of a comparison between three groups of patients (total 88 patients) with advanced gastric cancer with positive cytology at peritoneal lavage but without peritoneal metastases undergone to surgical resection alone or surgical resection associated either to intraperitoneal chemotherapy or to intraperitoneal chemotherapy plus peritoneal lavage. The 5-year survival rate of the patients who had intraperitoneal chemotherapy plus peritoneal lavage was $43.8 \%$, in the intraperitoneal chemotherapy group was $4.6 \%$ and in the surgery alone group was $0 \%(P=0.0001)$. The median survival time of the intraperitoneal chemotherapy plus peritoneal lavage group, intraperitoneal chemotherapy group, and surgery alone group were 35,16 , and 15 months, respectively. The multivariate analysis showed that the peritoneal lavage is the only significant factor affecting the prognosis. 


\section{FUTURE PROSPECTS}

Beyond the scope of this view are many promising new directions for prevention and treatment of peritoneal metastases from gastric cancer. Targeted therapies may be of great value for subsets of patients, such as those who are HER2-positive (ToGA Study) ${ }^{[76]}$. Also, pressurized intraperitoneal aerosol chemotherapy may substitute for NIPS in preparing patients for subsequent potentially curative resection of all clinically evident disease $^{[77]}$. As these new treatments develop controlled trials comparing the new strategies will be necessary.

\section{DECLARATIONS}

Authors' contributions

Sugarbaker PH contributed solely to the paper.

\section{Financial support and sponsorship}

None.

\section{Conflicts of interest}

There are no conflicts of interest.

\section{Patient consent}

Not applicable.

\section{Ethics approval}

Not applicable.

\section{Copyright}

(c) The Author(s) 2018.

\section{REFERENCES}

1. Berretta M, Fisichella R, Borsatti E, Lleshi A, Ioffredo S, Meneguzzo N, Canzonieri V, Di Grazia A, Cannizzaro R, Tirelli U, Berretta S. Feasibility of intraperitoneal Trastuzumab treatment in a patient with peritoneal carcinomatosis from gastric cancer. Eur Rev Med Pharmacol Sci 2014;18:689-92.

2. Jemal A, Bray F, Center MM, Ferlay J, Ward E, Forman D. Global cancer statistics. CA Cancer J Clin 2011;61:69-90.

3. Sarela AI, Miner TJ, Karpeh MS, Coit DG, Jaques DP, Brennan MF. Clinical outcomes with laparoscopic stage M1, unresected gastric adenocarcinoma. Ann Surg 2006;243:189-95.

4. Brenner H, Rothenbacher D, Arndt V. Epidemiology of stomach cancer. Methods Mol Biol 2009;472:467-77.

5. Cappellani A, Zanghi A, Di Vita M, Zanet E, Veroux P, Cacopardo B, Cavallaro A, Piccolo G, Lo Menzo E, Murabito P, Berretta M. Clinical and biological markers in gastric cancer: update and perspectives. Front Biosci (Schol Ed) 2010;2:403-12.

6. Hioki M, Gotohda N, Konishi M, Nakagohri T, Takahashi S, Kinoshita T. Predictive factors improving survival after gastrectomy in gastric cancer patients with peritoneal carcinomatosis. World J Surg 2010;34:555-62.

7. Sugarbaker PH, Yu W, Yonemura Y. Gastrectomy, peritonectomy, and perioperative intraperitoneal chemotherapy: the evolution of treatment strategies for advanced gastric cancer. Semin Surg Oncol 2003;21:233-48.

8. Glehen O, Mohamed F, Gilly FN. Peritoneal carcinomatosis from digestive tract cancer: new management by cytoreductive surgery and intraperitoneal chemohyperthermia. Lancet Oncol 2004;5:219-28.

9. Elias D, Gilly F, Boutitie F, Quenet F, Bereder JM, Mansvelt B, Lorimier G, Dubè P, Glehen O. Peritoneal colorectal carcinomatosis treated with surgery and perioperative intraperitoneal chemotherapy: retrospective analysis of 523 patients from a multicentric French study. J Clin Oncol 2010;28:63-8.

10. Yan TD, Deraco M, Baratti D, Kusamura S, Elias D, Glehen O, Gilly FN, Levine EA, Shen P, Mohamed F, Moran BJ, Morris DL, Chua TC, Piso P, Sugarbaker PH. Cytoreductive surgery and hyperthermic intraperitoneal chemotherapy for malignant peritoneal mesothelioma: multi-institutional experience. J Clin Oncol 2009;27:6237-42.

11. Sugarbaker PH. New standard of care for appendiceal epithelial neoplasms and pseudomyxoma peritonei syndrome? Lancet Oncol 2006;7:69-76

12. Gunderson LL, Sosin H. Adenocarcinoma of the stomach: areas of failure in a re-operation series (second or symptomatic look) clinicopathologic correlation and implications for adjuvant therapy. Int J Radiat Oncol Biol Phys 1982;8:1-11.

13. Wisbeck WM, Becher EM, Russell AH. Adenocarcinoma of the stomach: autopsy observations with therapeutic implications for the radiation oncologist. Radiother Oncol 1986;7:13-8. 
14. Landry J, Tepper JE, Wood WC, Moulton EO, Koerner F, Sullinger J. Patterns of failure following curative resection of gastric carcinoma. Int J Radiat Oncol Biol Phys 1990;19:1357-62.

15. Wils J, Meyer HJ, Wilke H. Current status and future directions in the treatment of localized gastric cancer. Ann Oncol 1994;5 Suppl 3:69-72.

16. Maruyama K, Okabayashi K, Kinoshita T. Progress in gastric cancer surgery in Japan and its limits of radicality. World J Surg 1987;11:418-25.

17. Kaibara N, Sumi K, Yonekawa M, Ohta M, Makino M, Kimura O, Nishidoi H, Koga S. Does extensive dissection of lymph nodes improve the results of surgical treatment of gastric cancer? Am J Surg 1990;159:218-21.

18. Korenaga D, Moriguchi S, Orita H, Kakeji Y, Haraguchi M, Maehara Y, Sugimachi K. Trends in survival rates in Japanese patients with advanced carcinoma of the stomach. Surg Gynecol Obstet 1992;174:387-93.

19. Boku T, Nakane Y, Minoura T, Takada H, Yamamura M, Hioki K, Yamamoto M. Prognostic significance of serosal invasion and free intraperitoneal cancer cells in gastric cancer. Br J Surg 1990;77:436-9.

20. Fujimoto S, Takahashi M, Mutou T, Kobayashi K, Toyosawa T, Isawa E, Sumida M, Ohkubo H. Improved mortality rate of gastric carcinoma patients with peritoneal carcinomatosis treated with intraperitoneal hyperthermic chemoperfusion combined with surgery. Cancer 1997;79:884-91.

21. Kodera Y, Yamamura Y, Shimizu Y, Torii A, Hirai T, Yasui K, Morimoto T, Kato T. Peritoneal washing cytology: prognostic value of positive findings in patients with gastric carcinoma undergoing a potentially curative resection. J Surg Oncol 1999;72:60-4; discussion 64-5.

22. Bando E, Yonemura Y, Takeshita Y, Taniguchi K, Yasui T, Yoshimitsu Y, Fushida S, Fujimura T, Nishimura G, Miwa K. Intraoperative lavage for cytological examination in 1,297 patients with gastric carcinoma. Am J Surg 1999;178:256-62.

23. Fujimura T, Yonemura Y, Ninomiya I, Miwa K, Miyazaki I, Endo Y, Ishikawa N, Obata T, Tanaka M, Sasaki T. Early detection of peritoneal dissemination of gastrointestinal cancers by reverse-transcriptase polymerase chain reaction. Oncol Rep 1997;4:1015-9.

24. Marutsuka T, Shimada S, Shiomori K, Hayashi N, Yagi Y, Yamane T, Ogawa M. Mechanisms of peritoneal metastasis after operation for non-serosa-invasive gastric carcinoma: an ultrarapid detection system for intraperitoneal free cancer cells and a prophylactic strategy for peritoneal metastasis. Clin Cancer Res 2003;9:678-85.

25. Takebayashi K, Murata S, Yamamoto H, Ishida M, Yamaguchi T, Kojima M, Shimizu T, Shiomi H, Sonoda H, Naka S, Mekata E, Okabe H, Tani T. Surgery-induced peritoneal cancer cells in patients who have undergone curative gastrectomy for gastric cancer. Ann Surg Oncol 2014;21:1991-7.

26. Arita T, Ichikawa D, Konishi H, Komatsu S, Shiozaki A, Hiramoto H, Hamada J, Shoda K, Kawaguchi T, Hirajima S, Nagata H, Fujiwara H, Okamoto K, Otsuji E. Increase in peritoneal recurrence induced by intraoperative hemorrhage in gastrectomy. Ann Surg Oncol 2015;22:758-64.

27. Sethna KS, Sugarbaker PH. New prospects for the control of peritoneal surface dissemination of gastric cancer using perioperative intraperitoneal chemotherapy. Cancer Ther 2004;2:79-84.

28. Los G, Mutsaers PH, Lenglet WJ, Baldew GS, McVie JG. Platinum distribution in intraperitoneal tumors after intraperitoneal cisplatin treatment. Cancer Chemother Pharmacol 1990;25:389-94.

29. Xu DZ, Zhan YQ, Sun XW, Cao SM, Geng QR. Meta-analysis of intraperitoneal chemotherapy for gastric cancer. World J Gastroenterol 2004;10:2727-30.

30. Yan TD, Black D, Sugarbaker PH, Zhu J, Yonemura Y, Petrou G, Morris DL. A systematic review and meta-analysis of the randomized controlled trials on adjuvant intraperitoneal chemotherapy for resectable gastric cancer. Ann Surg Oncol 2007;14:2702-13.

31. Feingold PL, Kwong ML, Sabesan A, Sorber R, Rudloff U. Cytoreductive surgery and hyperthermic intraperitoneal chemotherapy for gastric cancer and other less common disease histologies: is it time? J Gastrointest Oncol 2016;7:87-98.

32. Yonemura Y, Kawamura T, Bandou E, Takahashi S, Sawa T, Matsuki N. Treatment of peritoneal dissemination from gastric cancer by peritonectomy and chemohyperthermic peritoneal perfusion. Br J Surg 2005;92:370-5.

33. Glehen O, Gilly FN, Arvieux C, Cotte E, Boutitie F, Mansvelt B, Bereder JM, Lorimier G, Quenet F, Elias D; Association Française de Chirurgie. Peritoneal carcinomatosis from gastric cancer: a multi-institutional study of 159 patients treated by cytoreductive surgery combined with perioperative intraperitoneal chemotherapy. Ann Surg Oncol 2010;17:2370-7.

34. Hall JJ, Loggie BW, Shen P, Beamer S, Douglas Case L, McQuellon R, Geisinger KR, Levine EA. Cytoreductive surgery with intraperitoneal hyperthermic chemotherapy for advanced gastric cancer. J Gastrointest Surg 2004;8:454-63.

35. Yu W, Whang I, Chung HY, Averbach A, Sugarbaker PH. Indications for early postoperative intraperitoneal chemotherapy of advanced gastric cancer: results of a prospective randomized trial. World J Surg 2001;25:985-90.

36. Sadeghi B, Arvieux C, Glehen O, Beaujard AC, Rivoire M, Baulieux J, Fontaumard E, Brachet A, Caillot JL, Faure JL, Porcheron J, Peix JL, François Y, Vignal J, Gilly FN. Peritoneal carcinomatosis from non-gynecologic malignancies: results of the EVOCAPE 1 multicentric prospective study. Cancer 2000;88:358-63.

37. Boku N; Gastrointestinal Oncology Study Group of Japan Clinical Oncology Group. Chemotherapy for metastatic disease: review from JCOG trials. Int J Clin Oncol 2008;13:196-200.

38. Hirose K, Katayama K, Iida A, Yamaguchi A, Nakagawara G, Umeda S, Kusaka Y. Efficacy of continuous hyperthermic peritoneal perfusion for the prophylaxis and treatment of peritoneal metastasis of advanced gastric cancer: evaluation by multivariate regression analysis. Oncology 1999;57:106-14.

39. Rossi CR, Pilati P, Mocellin S, Foletto M, Ori C, Innocente F, Nitti D, Lise M. Hyperthermic intraperitoneal intraoperative chemotherapy for peritoneal carcinomatosis arising from gastric adenocarcinoma. Suppl Tumori 2003;2:S54-7.

40. Glehen O, Schreiber V, Cotte E, Sayag-Beaujard AC, Osinsky D, Freyer G, François Y, Vignal J, Gilly FN. Cytoreductive surgery and intraperitoneal chemohyperthermia for peritoneal carcinomatosis arising from gastric cancer. Arch Surg 2004;139:20-6.

41. Scaringi S, Kianmanesh R, Sabate JM, Facchiano E, Jouet P, Coffin B, Parmentier G, Hay JM, Flamant Y, Msika S. Advanced gastric 
cancer with or without peritoneal carcinomatosis treated with hyperthermic intraperitoneal chemotherapy: a single western center experience. Eur J Surg Oncol 2008;34:1246-52.

42. Yonemura Y, Fujimura T, Nishimura G, FallaR, Sawa T, Katayama K, Tsugawa K, Fushida S, Miyazaki I, Tanaka M, Endou Y, Sasaki T. Effects of intraoperative chemohyperthermia in patients with gastric cancer with peritoneal dissemination. Surgery 1996;119:437-44.

43. Sugarbaker PH, Deraco M, Glehen O, Helm CW, Morris DL, Van der Speeten K. Cytoreductive Surgery and Perioperative Chemotherapy for Peritoneal Surface Malignancy: Textbook and Video Atlas. Woodbury: Ciné-Med; 2012. p. 79-94.

44. Jacquet P, Sugarbaker PH. Clinical research methodologies in diagnosis and staging of patients with peritoneal carcinomatosis. Cancer Treat Res 1996;82:359-74.

45. Yonemura Y, Kawamura T, Bandou E, Takahashi S, Sawa T, Matsuki N. Treatment of peritoneal dissemination from gastric cancer by peritonectomy and chemohyperthermic peritoneal perfusion. Br J Surg 2005;92:370-5.

46. Yang XJ, Huang CQ, Suo T, Mei LJ, Yang GL, Cheng FL, Zhou YF, Xiong B, Yonemura Y, Li Y. Cytoreductive surgery and hyperthermic intraperitoneal chemotherapy improves survival of patients with peritoneal carcinomatosis from gastric cancer: final results of a phase III randomized clinical trial. Ann Surg Oncol 2011;18:1575-81.

47. Valle M, Van der Speeten K, Garofalo A. Laparoscopic hyperthermic intraperitoneal perioperative chemotherapy (HIPEC) in the management of refractory malignant ascites: a multi-institution retrospective analysis in 52 patients. J Surg Oncol 2009;100:331-4.

48. Glehen O, Gilly FN, Cotte E. Hyperthermic intraperitoneal chemotherapy in advanced gastric cancer: the end of skepticism? Ann Surg Oncol 2011;18:1524-6.

49. Jacquet P, Jelinek JS, Steves MA, Sugarbaker PH. Evaluation of computer tomography in patients with peritoneal carcinomatosis. Cancer 1993;72:1631-6.

50. Garofalo A, Valle M. Laparoscopy in the management of peritoneal carcinomatosis. Cancer J 2009;15:190-5.

51. Badgwell B, Cormier JN, Krishnan S, Yao J, Staerkel GA, Lupo PJ, Pisters PW, Feig B, Mansfield P. Does neoadjuvant treatment for gastric cancer patients with positive peritoneal cytology at staging laparoscopy improve survival? Ann Surg Oncol 2008;15:2684-91.

52. Cunningham D, Allum WH, Stenning SP, Thompson JN, Van de Velde CJ, Nicolson M, Scarffe JH, Lofts FJ, Falk SJ, Iveson TJ, Smith DB, Langley RE, Verma M, Weeden S, Chua YJ; MAGIC Trial Participants. Perioperative chemotherapy versus surgery alone for resectable gastroesophageal cancer. $N$ Engl J Med 2006;355:11-20.

53. Preusser P, Wilke H, Achterrath W, Fink U, Lenaz L, Heinicke A, Meyer J, Meyer HJ, Buente H. Phase II study with the combination etoposide, doxorubicin, and cisplatin in advanced measurable gastric cancer. J Clin Oncol 1989;7:1310-7.

54. Ajani JA, Ota DM, Jessup JM, Ames FC, McBride C, Boddie A, Levin B, Jackson DE, Roh M, Hohn D. Resectable gastric carcinoma. An evaluation of preoperative and postoperative chemotherapy. Cancer 1991;68:1501-6.

55. Yonemura Y, Bandou E, Sawa T, Yoshimitsu Y, Endou Y, Sasaki T, Sugarbaker PH. Neoadjuvant treatment of gastric cancer with peritoneal dissemination. Eur J Surg Oncol 2006;32:661-5.

56. Sugarbaker PH. Peritonectomy procedures. Ann Surg 1995;221:29-42.

57. Yonemura Y, Fujimura T, Fushida S, Fujita H, Bando E, Taniguchi K, Nishimura GI, Miwa K, Ohyama S, Sugiyama K, Sasaki T, Endo Y. Peritonectomy as a Treatment Modality for Patients with Peritoneal Dissemination from Gastric Cancer. In: Nakajima T, Yamaguchi T, editors. Multimodality Therapy for Gastric Cancer. Tokyo: Springer Japan; 1999. p. 71-80.

58. Canbay E, Mizumoto A, Ichinose M, Ishibashi H, Sako S, Hirano M, Takao N, Yonemura Y. Outcome data of patients with peritoneal carcinomatosis from gastric origin treated by a strategy of bidirectional chemotherapy prior to cytoreductive surgery and hyperthermic intraperitoneal chemotherapy in a single specialized center. Ann Surg Oncol 2014;21:1147-52.

59. Kitayama J, Ishigami H, Yamaguchi H, Yamashita H, Emoto S, Kaisaki S, Watanabe T. Salvage gastrectomy after intravenous and intraperitoneal paclitaxel 9PTX0 administration with oral S-1 for peritoneal dissemination of advanced gastric cancer with malignant ascites. Ann Surg Oncol 2014;21:539-46.

60. Fujiwara Y, Takiguchi S, Nakajima K, Miyata H, Yamasaki M, Kurokawa Y, Mori M, Doki Y. Intraperitoneal docetaxel combined with S-1 for advanced gastric cancer with peritoneal dissemination. J Surg Oncol 2012;105:38-42.

61. Al-Batran SE, Homann N, Pauligk C, Illerhaus G, Martens UM, Stoehlmacher J, Schmalenberg H, Luley KB, Prasnikar N, Egger M, Probst S, Messmann H, Moehler M, Fischbach W, Hartmann JT, Mayer F, Höffkes HG, Koenigsmann M, Arnold D, Kraus TW, Grimm K, Berkhoff S, Post S, Jäger E, Bechstein W, Ronellenfitsch U, Mönig S, Hofheinz RD. Effect of neoadjuvant chemotherapy followed by surgical resection on survival in patients with limited metastatic gastric or gastroesophageal junction cancer. JAMA Oncol 2017;3:123744 .

62. Walker JL, Armstrong DK, Huang HQ, Fowler J, Webster K, Burger RA, Clarke-Pearson D. Intraperitoneal catheter outcomes in a phase 3 trial of intravenous vs. intraperitoneal chemotherapy in optimal stage III ovarian and primary peritoneal cancers: a Gynecologic Oncology Group study. Gynecol Oncol 2006;100:27-32.

63. Yonemura Y, Elnemr A, Endou Y, Ishibashi H, Mizumoto A, Miura M, Li Y. Effects of neoadjuvant intraperitoneal/systemic chemotherapy (bidirectional chemotherapy) for the treatment of patients with peritoneal metastases from gastric cancer. Int J Surg Oncol 2012;2012:148420.

64. Sugarbaker PH, Steves MA, Hafner GH. Treatment of peritoneal carcinomatosis from colon or appendiceal cancer with induction intraperitoneal chemotherapy. Reg Cancer Treat 1993;4:183-7.

65. Sugarbaker PH, Alderman R, Edwards G, Marquardt CE, Gushchin V, Esquivel J, Chang D. Prospective morbidity and mortality assessment of cytoreductive surgery plus perioperative intraperitoneal chemotherapy to treat peritoneal dissemination of appendiceal mucinous malignancy. Ann Surg Oncol 2006;13:635-44.

66. Yan TD, Edwards G, Alderman R, Marquardt CE, Sugarbaker PH. Morbidity and mortality assessment of cytoreductive surgery and perioperative intraperitoneal chemotherapy for diffuse malignant peritoneal mesothelioma - a prospective study of 70 consecutive cases. Ann Surg Oncol 2007;14:515-25.

67. Cunliffe WJ. The rationale for early postoperative intraperitoneal chemotherapy for gastric cancer. Cancer Treat Res 1991;55:143-59. 
68. Morgan RJ Jr, Doroshow JH, Synold T, Lim D, Shibata S, Margolin K, Schwarz R, Leong L, Somlo G, Twardowski P, Yen Y, Chow W, Lin P, Paz B, Chu D, Frankel P, Stalter S. Phase I trial of intraperitoneal docetaxel in the treatment of advanced malignancies primarily confined to the peritoneal cavity: dose-limiting toxicity and pharmacokinetics. Clin Cancer Res 2003;9:5896-901.

69. Fushida S, Nao F, Kinami S, Ninomiya I, Fujimura T, Nishimura G, Ohta T, Yokogawa K, Miyamoto K, Miwa K. Pharmacologic study of intraperitoneal docetaxel in gastric cancer patients with peritoneal dissemination. Gan To Kagaku Ryoho 2002;29:1759-63. (in Japanese)

70. Malmström H, Larsson D, Simonsen E. Phase I study of intraperitoneal carboplatin as adjuvant therapy in early ovarian cancer. Gynecol Oncol 1990;39:289-94.

71. Ohno M1, Hirokawa M, Hando T. Pharmacokinetics of carboplatin after intraperitoneal administration and clinical effect in ovarian cancer. Gan To Kagaku Ryoho 1992;19:2355-61. (in Japanese)

72. Boku T, Nakane Y, Minoura T, Takada H, Yamamura M, Hioki K, Yamamoto M. Prognostic significance of serosal invasion and free intraperitoneal cancer cells in gastric cancer. Br J Surg 1990;77:436-9.

73. Coccolini F, Catena F, Glehen O, Yonemura Y, Sugarbaker PH, Piso P, Ceresoli M, Montori G, Ansaloni L. Effect of intraperitoneal chemotherapy and peritoneal lavage in positive peritoneal cytology in gastric cancer. Systematic review and meta-analysis. Eur J Surg Oncol 2016;42:1261-7.

74. Shimada S, Tanaka E, Marutsuka T, Honmyo U, Tokunaga H, Yagi Y, Aoki N, Ogawa M. Extensive intraoperative peritoneal lavage and chemotherapy for gastric cancer patients with peritoneal free cancer cells. Gastric Cancer 2002;5:168-72.

75. Kuramoto M, Shimada S, Ikeshima S, Matsuo A, Yagi Y, Matsuda M, Yonemura Y, Baba H. Extensive intraoperative peritoneal lavage as a standard prophylactic strategy for peritoneal recurrence in patients with gastric carcinoma. Ann Surg 2009;250:242-6.

76. ToGA Study - A Study of Herceptin (Trastuzumab) in Combination With Chemotherapy Compared With Chemotherapy Alone in Patients With HER2-Positive Advanced Gastric Cancer. ClinicalTrials.gov Identifier: NCT01041404. Available from: https://clinicaltrials.gov/ ct2/show/NCT01041404 [Last accessed on 4 Jan 2018]

77. Intraperitoneal Aerosol Chemotherapy in Gastric Cancer (PIPAC-GA01). ClinicalTrials.gov Identifier: NCT01854255. Available from: https://clinicaltrials.gov/ct2/show/NCT01854255 [Last accessed on 4 Jan 2018] 